\title{
Marking the Moral Boundaries of Class
}

\author{
by John Kirk \\ London Metropolitan University \\ Sociological Research Online, Volume 11, Issue 1, \\ $<$ http://unw.socresonline.org.uk/11/1/kirk.html> \\ doi:10.5153/sro. 1260
}

Received: 22 Nov 2005 Accepted: 15 Mar 2006 Published: 31 Mar 2006

\begin{abstract}
This article welcomes the recent renewed interest in the topic of class within sociology and cultural studies. This comes after a long period - from around the middle part of the 1980s and into the 1990s during which social class was dismissed as a mode of understanding socio-economic and cultural conditions on the part of both academics and mainstream political organisations alike. Working-class formations in particular came under scrutiny, increasingly seen to be in terminal decline and fragmentation through the impact of post-industrialisation processes set in train in western economies from the turn of the 1980s onwards. The demise of heavy industry - steel, coal, textiles, for instance - profoundly altered working-class communities, transforming the material world and cultural life of the British working class, powerful developments reinforcing the 'end of class' debate. Allied to this, the emergence within the academy of new theoretical frameworks associated with postmodern thought claimed to undermine traditional understandings around class. This article insists on the continuing significance of class and does so by focussing on an important recent response to the class debate, Andrew Sayer's The Moral Significance of Class (2005). This book stakes a lucid claim for the importance of recognising class as a powerful determining factor of subjectivity. While drawing upon aspects of Sayer's theoretical framework and argument to examine class experience, it is also the intention of the article to supplement Sayer's work by developing related theoretical propositions derived from the writing of Raymond Williams and the Russian linguist and cultural critic Volosinov/Bakhtin.
\end{abstract}

\section{Keywords: Working Class; Experience; Structure of Feeling; Recognition; Language; Identity}

\section{Introduction}

1.1 Recent times have seen a resurgent interest in the study of class within academia, particularly with regard to the working class. This represents a welcome development in the wake of a long period during which social class received scant interest as a mode of understanding socio-economic and cultural conditions on the part of both academics and mainstream political organisations alike. Indeed, the common invocation, from around the middle part of the 1980s and into the 1990s, has been that of the 'end of class'. A particular emphasis within this argument fell on working-class formations, seen to be in terminal decline and hopeless fragmentation through the impact of post-industrialisation processes set in train in western economies - Britain and the USA in particular - from the turn of the 1980s onwards. As traditional industries closed down - those of steel, coal, textiles, for instance - and working-class communities folded under the strains, the material world and cultural life of the British working class was seen by commentators to be increasingly obsolete, extinct and, within only a few short years, the object only of heritage spectacles and exercises in nostalgia.

1.2 With the eclipse of class as object of study or agency for political change came a fresh interest in other modes of cultural identity, most specifically around the categories of race, gender and sexuality. This concern inaugurated a new 'identity politics', within the broader context of postmodernity. This new politics developed theoretical approaches for studying subjectivity, approaches derived from post-structuralist thinking as well as a resurgent feminism. Such influences were felt particularly in cultural studies and cognate disciplines, including sociology. While some of these positions did draw class within the orbit of study around race and gender for instance, it quite quickly became apparent that - in the words of one commentator - class would lose out, coming only to constitute the 'lost identity of identity politics.' (Medhurst, 2000: 34) The one notable and consistent exception here - though he was not working within a 
British context - was the work of French sociologist Pierre Bourdieu, whose authority and influence proved sharper in sociology rather than cultural studies. Nevertheless, the general sense remained, in both disciplines - further reinforced by key studies from writers like Giddens (1991) and Beck (1986) - that class was passé.

1.3 The purpose of this article is less to explore the detailed reasons behind the demise of class within key academic disciplines and political thinking more generally as I have commented on this elsewhere (Kirk, 2003), but more to do with welcoming its renaissance, at least within some academic circles. To undertake this task I will start by examining an important recent response to the class debate, Andrew Sayer's The Moral Significance of Class (2005). This book stakes a lucid claim for the continued significance of class as a powerful determining factor of subjectivity, and though the study is chiefly concerned with the phenomenon of classes broadly speaking, a central part of the argument focuses on working-class experience and identity. In the book, Sayer establishes a compelling framework for thinking class as not merely an objective position within relations of production - whereby, in relation to working or "lower" classes, not only exploitation occurs, but material deprivations exist - but also as a category, or formation, through which deeply moral and ethical questions are lived and experienced on a daily basis: experiences imbued with class assumptions and ascriptions and thus ones that must be seriously acknowledged and engaged. In doing this, Sayer contributes to an emergent impulse in recent writing about working-class experience; an impulse first found in some key analyses by women scholars from around the mid 1990s. Exploring the subjective dimensions of working-class life, this work contradicted proclamations on the end of class. The writing focused less on the political economy of class - though it by no means ignored it - to explore instead the border-lines between class and gender, as well as the anxieties felt in being dis-located from one's class of origin. This was often undertaken in relation to their positions within the academy, existing within what might be termed the class cultural cusp. ${ }^{[1]}$ In doing this, the work cast fresh light on neglected dimensions of working-class subjectivity, expanding the boundaries of study in this area by insisting on the intersection of class and gender, and foregrounding what we might call the "emotional" politics of class, representing a turn away from some of the more economistic models common to alternative theoretical frameworks for evaluating class in the past. This important work has continued and, as Sayer's book attests, is being extended into other areas and concerns.

1.4 The second purpose of this article is to draw upon aspects of Sayer's theoretical framework and his book's thematic concerns to examine a range of class articulations and experiences through an analysis of contemporary working-class autobiographical writing. Where Sayer's work opens up questions of a deeply moral nature - issues around dignity and recognition, for instance, in the context of profound inequalities autobiographical writing engages with these same concerns, explores very similar structures of feeling, at the level of experience. The reference to structure of feeling signals a further aim of this piece. While Sayer relies heavily on key ideas derived from Bourdieu, it is my intention to supplement these by developing related theoretical propositions taken from the work of Raymond Williams and the Russian linguist and cultural critic Volosinov/Bakhtin. ${ }^{[2]}$ In doing this, I hope to show that Williams's concept structure of feeling has a greater capacity to flag up the cognitive dimensions of feeling than does Bourdieu's notion of habitus (Sayer, as we will see below, is critical of Bourdieu on this score, too); while employing the ideas of Bakhtin/Volosinov foregrounds the centrality of language for understanding working-class identity.

1.5 The Moral Significance of Class takes as its focus the subjective dimensions of class experience. Sayer sets out his position early on: 'class matters to us', he remarks, 'not only because of differences in material wealth and economic security, but also because it affects our access to things, relationships, experiences and practices, which we have reason to value, and hence our chances of living a fulfilling life.' (2005: 1) This takes us to the heart of some of the central categories and arguments which inform the study - deference and shame, dignity and respect, and how these sentiments are withheld from or ascribed to others in a culture and society shaped by class inequality and difference. These sentiments and emotions are essentially moral ones, he argues, and they are important for a range of reasons, the least of which being that they profoundly matter to people. For Sayer, class is essential to understanding this. Class inequalities in terms of wealth and power persist - indeed, are intensifying - but these are further compounded by the way people are forced to negotiate their subjective responses to class positioning, so that 'to understand the subjective experience of class we need to consider the emotional and evaluative aspects of the relations of self to self and self to other.' (2005: 22) The book throws up important questions around class that not only shed light on the continued significance of class as an economic category, but also illuminate a crucial moral dimension to class relations which goes to the very heart of what it is be valued as a human being.

\section{Habitus and habitat}

2.1 Sayer's argument around the moral significance of class employs Bourdieu's celebrated notion of the habitus throughout, though he sets out to modify it. Bourdieu argues that action is interpreted through the 
concept of habitus. The internalised structure of the habitus acts as a classifying mechanism for making sense of the world - embedded dispositions generating in the subject an almost spontaneous response to the world they inhabit: a kind of 'feel for the game', or a 'design for life'. The dispositions constituting the habitus, when activated, work to reproduce the social structures which shaped them in the first place, thus reflecting for Sayer the 'habitat in which they were formed.' (2005: 24). And they are relational so that, in dialogical fashion, the dispositions are always oriented towards some other(s).

2.2 The notion of subconscious, bodily learning which makes up the habitus, and which attunes individuals to the circumstances of their existence, undercuts a sense of resistance in Bourdieu's take on subjectivity, it has been argued. The embodied dispositions which constitute the habitus, and which regulate behaviour as part of the processes of socialisation and adaptation to the way things are, has led Bourdieu's concept to be aligned with notions of compliance and acceptance. This is seen to imply a pessimistic conception of human subjectivity, 'a model of a perfectly malleable human, a model which makes it impossible to understand how anyone could react against and resist at least some parts of their habitat.' (Sayer 2005: 31)

2.3 Yet while the habitus is a map for negotiating familiar terrain, it is not necessarily the key for understanding the self as a unitary entity for, as Bourdieu states, there can be contradictory entities making up the habitus though these too will be internalised. For Sayer, this 'model of development is one of subconscious bodily learning through repetition and practice'; but Sayer's main point is to insist on a process beyond, or accompanying, this, one which Bourdieu's own formulations critically downplay. This is the degree to which the habitus is also constituted through a level of rational, conscious monitoring based on ethical considerations. In this view, 'embodiment and rationality are not as opposed as generally assumed.' (2005: 28) The reflexive element characteristic of individuals' actions stands as a key component of the habitus, a feature that Bourdieu under-valued and one that Sayer wants to rescue. Placing a sharper emphasis on conscious reflection, on how individuals continually interpret and understand various discourses - those which constitute the habitus, and those at variance with it - means that 'embodiment and rationality are not opposed.' (2005: 28) Thus, in different terms, thought and feeling do not stand in some kind of binary opposition, so that feeling can constitute a mode of cognition, of evaluative understanding.

2.4 Sayer explains this by pointing out that feelings of pride, shame, fear or envy may well be embodied ones in the sense Bourdieu implies, but they are also a means of understanding and engaging with the world. As sentiments, though, they may be unevenly distributed: one's share of shame, pride, envy or fear will always be shaped in profound ways by unequal social relations. Moreover, Sayer insists, emotions are evaluative responses which derive from a range of causes and effects. They can be culturally, or discursively, constructed only in so far as they exist in the first place. (2005: 38) In this sense, culture does not go all the way down - it does not fully determine, but mediates. So it is that the habitus has a necessary moral dimension: 'ethical dispositions develop through socialisation and are not reducible to expressions of mere interest, nor are the norms with which they are associated reducible to mere conventions.' (2005: 51) Indeed, Sayer adds, 'they have a normative force deriving from their implications in well-being.' (2005: 51) This leads on to what we can call the individual's take up, acceptance and adherence to commitments and to the desire for recognition.

\section{Recognition}

3.1 Part of Sayer's critique involves developing interesting perspectives on the current vogue for the politics of recognition. Such politics have in recent times taken up the dominant position with some on the left, certainly within academia. In this politics, economic justice, or re-distribution, is sidelined in favour of cultural recognition, where the subaltern is finally allowed to "speak", and where oppressed identities predicated on formations of race, gender and sexuality might acquire greater acknowledgment. Respect for cultural difference is based on an assertion that seems to regard the principle of recognition as a fundamental right and human need. That such positions can have the anomalous effect of legitimising racist ideas - white and black cultures are different and therefore should remain separate, can give great succour to fascist groupings or tendencies - highlights one of the weak links of this mode of understanding which predominantly informs current identity politics. Nevertheless its hegemonic status is generally accepted. When we consider the position in relation to class, it is, as Sayer suggests, of some use but also problematic. Though the economics of class, in terms of a range of capitals as described by Bourdieu, remains central to understandings of inequality and access to power, class politics is, and has always been, strongly driven also by moral concerns and a sense of injustice. Thus alongside the concern with inequality and re-distribution, Sayer argues, understandings of class must also take cognisance of the desire for recognition, which emerges as a central pre-occupation in terms of 'the micro- and macro-politics of class.' (2005: 53) 
been fought through the workplace environment or the communal space in which class is lived. At a very straightforward level, the battle to secure the vote for working men and women - fought throughout the nineteenth and twentieth centuries - constitutes a call for recognition aimed towards those intent on concentrating power and influence to themselves. Indeed, this is what we might call, in contemporary idiom, struggles over notions of citizenship. Trade unions function not only to ensure the full fruits of labour, in terms of material reward, go to workers, but that workers receive their full entitlement of recognition and respect for the essential contribution they make to the wealth and well-being of the nation. Axel Honneth makes a very similar point, showing how the 'labour movements of the late $19^{\text {th }}$ and early $20^{\text {th }}$ centuries' built into political and economic demands the 'aim of gaining recognition for people's own traditions and ways of life, within the ambit of capitalist values.' (Honneth 2001: 53). There are processes occurring here the act of demanding recognition implies, or foregrounds, the essentially dialogic relations which constitute the social and which can be, and are seen to be within a range of contexts, articulated in antagonistic terms. Recognition suggests de- or mis-recognition: the othering which also constitutes notions of the self. Relations of domination emerge from this, as well as relations based on solidarity. There are appropriate cultural forms through which recognition can be demanded - indeed, the picket line might be one of these. Other forms through which recognition can be explored and announced can be through the representations, arguments and perspectives found in worker autobiographies, for instance, where the writer might seek both recognition and affirmation of a life well, or nobly, lived. This is something I will return to later on.

3.3 For Sayer, the importance of recognition lies in his understanding of 'symbolic domination' and how this is compounded by economic inequality so that the desire for recognition need not contradict, nor stand in opposition to, the politics of redistribution. The two things interact, sometimes closely bound together in subjects' articulations, sometimes separated out. Indeed, when people seek recognition for the work that they do, this recognition, as suggested above, is not always demanded in terms of monetary reward alone. Moreover, in some occupations, the desire for recognition and respect may be the primary motivation for those involved in the work.

\section{Commitments}

4.1 The idea of commitment rests largely on the metaphor of investment. But the rhetoric here of economic self-interest - what Sayer calls 'rational calculation' - is not the full picture as the concept of investment can also suggest a deep emotional commitment to something that means more than utilitarian or material reward. Sayer points out that 'the concept of commitments is superior to that of investments ... because it implies a more stronger and serious attachment, one that has an emotional dimension and involves objects, practices, others and relationships which we care about.' (2005: 40) Commitments clearly vary, both in intensity and kind. A commitment to a particular political ideology or position will carry greater intensity than a commitment to a brand of soap powder, even though advertisers will hope not. For Sayer, commitments become the very stuff of character: without them, he posits, 'we are likely to feel rootless or lost'; and 'losing or being prevented from pursuing commitments we have already formed leads to something akin to bereavement, since through our commitment to $x, x$ has captured something of us.' (2005: 41) This is self-evident in personal relationships, but also with regard to the public sphere, and how we earn or acquire our sense of identity and moral worth there. Sayer argues that forming commitments is what life amounts to in the end, so that 'the most important struggles of the social field concern those over commitments.' (2005: 127). But the commitment we can make will be dependent on the types of resources at our disposal, resources that will be unevenly distributed. This takes us back to notions of the habitus the cultural capital of middle-class parents will enable a more comprehensive commitment to their child's education than the cultural (or economic, for that matter) capital of a working-class parent. This does not mean that the working-class parent will not be committed to their child's education, only that they will find it much more difficult to fulfil that commitment without the pre-requisite social, economic and cultural capital that will enable them to 'play the game.' This can have profound ramifications, not only for the child's progress through education and for his/her future quality of life, but for the working-class parent's sense of self-worth, too, in that 'working-class people may feel unable to attempt to enter those places ["superior" educational institutions] not only because they will experience prejudice but because they feel that indeed they might not be worthy of them.' (Sayer 2005: 132)

4.2 We can take the idea of commitment further too, examining other aspects of the social field. An obvious location in which the need and desire to commit oneself to something lies in the world of work, and it is not uncommon in this sphere for people to perform "beyond the call of duty." This links to our discussion of recognition: work and identity are bound up with issues of fairness, respect, dignity and recognition. Sayer makes a very similar point, suggesting that any range of conflicts or affiliations in the workplace constitute powerful and sometimes overwhelming experiences for workers; so much so that 'mixtures of ambition, struggle for self-esteem and emotional commitment ... can have a huge impact on workers' lives - at the extreme, prompting them to leave secure jobs and uproot their lives.' (2005: 42) 
4.3 Work, while a necessity, can be and very often is one of those practices that people care about. But if current debates concerning the demise of work hold good, then an important means of valuing oneself, others and the wider world has been radically eclipsed. At the same time, if work is, or has become, degrading or alienating in its very nature (for some commentators - most notably Marx - capitalist social relations always already ensured this anyway), how can such commitments form and for what would one be asking recognition? Some of the ramifications of such outcomes for the individuals concerned can be heard in the voices of workers in Bourdieu's The Weight of the World (1999). Found in some of those narratives documented by Bourdieu and his team are not only articulations of pain and loss, but confusion, anger and despair: responses in part to this very loss or lack of recognition and to the end or impossibility of commitment. A society failing to inspire modes of commitment in its citizens, or offer means of acquiring meaningful recognition, might be seen to be running the risk of collapse. Hegemonic modes based on consent would have to be replaced by ones driven by coercion if the dominant were to maintain its power and privilege. Those critics who favour the end of work position, for instance, point to the transition in the west from societies of production to societies of consumption (or spectacle). Thus, through re-orientating the individual's sense of self to consumerism, where work is out of the frame and where value and selfrespect can be differently acquired, work no longer constitutes the sphere of commitment and vehicle for recognition it once did. This is a very powerful and influential argument. As an aside, however, it is important to recognise that consumption, like everything else, is shaped by class in terms of accessibility to resources, status demarcation, quality and symbolic value, and to assume that those at the bottom end of the market fail to register the degraded nature of the products which they may not - or no longer - make but consume is of course to partake in a form of class contempt.

\section{Ethos}

5.1 With regard to some of the observations made in the last section, it might be useful to consider here Bourdieu's idea of ethos. Bourdieu describes ethos as 'mortality made flesh'. $(1993,86)$ Thus he identifies the presence of a range of values embodied in the individual subject which regulate, implicitly, one's responses to the world and to others. This is a mode of practical knowledge wedded to the habitus. In relation to working-class experience, a key question stands out: what happens to such patterns of understanding following radical transformation in the social world - more specifically, the world of work and thus to the shape of people's lives? Simon Charlesworth argues that individuals or groups 'will consciously consider the ethics of their dispositions only when the principles one's actions embody cease to be part of the social world encountered.' (Charlesworth 2000: 31) There is another way of thinking about the concepts of ethos and habitus - and perhaps more fruitfully - and that is through Raymond Williams's notion of structure of feeling, a conceptual tool I will consider further on. Arguably, the concept of ethos is useful for understanding change both in terms of gender and generation - and in this view Raymond Williams's well-known assertion that 'no two generations speak the same language' holds particular resonance. Ethos, then, can be seen as something constitutive of the habitus, relating to guiding principles governing a life (articulated at both an individual and collective level), principles that only become more fully discursive when under pressure (suggesting Walter Benjamin's notion that the oppressed must 'seize hold of memory as it flashes up at a moment of danger', if not to be obliterated from history altogether). This notion of making discursive - particularly at moments of crisis or pressure - leads us in interesting ways to some of Mikhail Bakhtin's social and linguistic theory.

\section{Dialogics - or the making discursive practical consciousness}

6.1 Bakhtin's notion of the dialogic relations and structures characterising cultural conditions and social structure is for him expressed in the novel and its narrative forms and orientations. Such dialogics are the product of language as articulated experience, historically shaped and determined by external forces but also the available cultural conventions and positions for speaking identity and how those conventions are taken up, altered and used. Through this perspective, it is possible to consider the importance of narrating the self and think about the discursive nature of consciousness. Indeed, Bourdieu talks about dialogics in his opening comments in The Weight of the World (he calls it multiple perspectives, which relates to the Bakhtinian notion of polyphony, a condition of modernity within which dialogics is enmeshed), applying this approach to analysing the interviewee's responses there and this refers explicitly to literary technique and narrative analysis as a way of understanding what is going on.

6.2 Interestingly, in The Moral Significance of Class, Sayer draws our attention to what he calls 'internal conversations' (2005: 29) - exchanges within the self which make up a crucial aspect of our everyday existence. While acknowledging Bourdieu's critique of this position - that it threatens to project the contemplative relation to the world that is the specific condition of academic life and therefore represents, in Bourdieu's view, an unacceptable appropriation or colonisation of the everyday being-in-the-world more characteristic of those individuals and groups living in the world outside academia - he nevertheless insists that our 'streams of consciousness' - day-dreaming, considered ruminations, concentrated reflection on 
particular problems - 'are central to our lives', and he points to the interview transcripts in The Weight of the World that show actors churning 'through their moral narratives in their internal conversations almost obsessively.' (2005: 29)

6.3 These 'internal conversations' mirror in important ways what Bakhtin/Volosinov described as 'inner-voice discourse.' Consciousness is constituted, in this view, through multiple words that carry traces of the other voices; imagined listeners and speakers with whom a continuous dialogue is conducted. Inner-voice discourse is never strictly one's own. It posits a contradictory, or contested, consciousness based around complex ideas of experience, and constitutes the terrain of the dialogic within the wider sphere of heteroglossia. It is possible to regard these dialogic exchanges as representing evaluative accents related to social stratification and class differences (as well as gender relations), which constitute consciousness as characterised not by a single monologic structure (or a fully shaping habitus), but by levels of multivocality invoking the notion of dissonance, disclosing a view of language itself as the site of class antagonism and difference. For the Bakhtin of "Discourse and the Novel", dialogism is the very fabric of the modern novel form, but it is also a circumstance of everyday life, and it represents a struggle over meaning, a struggle for understanding oneself and one's position in the social order. From this view, then, utterance is a social act and communication is always organised in relation to some Other. (Dentith: 1995: 146)

Bakhtin/Volosinov developed such perspectives on language and communication partly in opposition to the Saussurean approach to the topic which prioritised the language system and its determining effects over the individual speech act: in other words, langue over parole. Rejecting Sausssure, they regarded the speech act and the language system as dialectically related. Thus: 'the actual reality of language-speech is not the abstract system of linguistic forms, not the isolated monologic utterance, and not the pyschophysiological act of implementation, but the social event of verbal interaction implemented in an utterance or utterances.' And context is vital in this view, so that, 'words are precisely the product of the reciprocal relationship between speaker and listener ... Each and every word expresses the one in relation to the other. I give myself verbal shape from another's point of view ... '(in Dentith 1995: 139) Raymond Williams describes such practices as 'a grasping of reality through language, which as practical consciousness is saturated by and saturates all social activity, including productive activity.' (Williams 1977: 37) Such understanding can inform narrative analysis of both work-life history testimonies and autobiographical writing, illuminating further those vital moral dimensions of class Sayer's work reveals. I will return to this point.

6.4 As language is inescapably social, it is part ours, part somebody else's. This view illuminates the possibility of an official and unofficial consciousness shaping subjective experience at any one time: a dialectic where the practices of everyday life may come into conflict with the prescriptions of authoritative/authorised discourse. This perspective has considerable echoes in Williams's notion of practical and official consciousness. The subject contests and engages with imagined listeners, but also with imagined world-views - and a term for understanding this is Raymond Williams's notion of structures of feeling. This concept implies not a formalised set of beliefs or values, but the flux and shift of these very forms themselves. And from this point of view, language is conceived as a ceaseless flow of utterance produced in dialogues between speakers in specific socio-historical contexts, from which contested and consensual positions take shape.

6.5 Part of this process involves analysing a complex stratification of what Bakhtin/Volosinov called speech-genres, which are in use all the time, articulating the relationship between speaker and listener, speaker and the world, in terms of power and status, individual and group, self and others. Language is stratified according to social activity, and speech-genres are seen to operate in the broader arena of what Bourdieu would call 'the linguistic market', constituting those areas of discursive exchange that Foucault defined differently as 'orders of discourse'. A speech-genre discloses a register or style - articulating sociocultural intentions and ideological positions, and to recognise this is to see speech-genres not merely as formally organised speech acts, but as practices entwined with the complex of values and beliefs constituting the social. Moreover, register inscribes a self-referential identity; one derived from a position in the social world, both as an individual and as part of a group and is linked to habitus as elaborated by Bourdieu, but also bound up with Williams's notion of structure of feeling. And it is to this that we now turn.

\section{Structures of feeling}

7.1 This leads us back, too, to some of our earlier discussions on Sayer and the habitus. Generally, critics have employed the concept of structure of feeling in the analysis of literary texts. In much of Williams's own work it is used in this way, but it has a broader use for making sense of cultural forms and formations and as social theory. Indeed, the concept holds a central place in Williams's work with regard to the notion of 'knowable community' - the idea of community being vital in a range of important ways to Williams's writing. And though the term structure of feeling may suggest a certain theoretical incompatibility or ambiguity with respect to cultural and social analysis - arguably a contradictory coupling, confusing the 
theoretical terrain rather than clarifying its borders or boundaries - the concept does combine the two cognitive processes of thought and feeling which Sayer had accused Bourdieu of neglecting in the development of his notion of habitus.

7.2 One of the most fruitful ways of approaching the theoretical implications of the term is to regard structure of feeling as part of Williams's critique of key aspects of post-structuralism. Peter Middleton has argued that the concept is grounded in a notion of experience and 'presence' that runs contrary to the antihumanism of much post-structuralist, and indeed some structuralist, thought. (Middleton 1989: 34) While Williams, for instance, may accept the post-structuralist view that experience cannot emerge pristine and uncontaminated by ideology, he still insists that we need not see all experience as ideological, or accept that the subject is merely an ideological illusion, a product of a set of discursive practices, or scripts. Williams claims the difficult term experience, at the same time rejecting the subject of bourgeois humanism, the sovereign individual with the capacity to act in the world unconstrained by structures and ideology. Thus, Middleton suggests: 'the concept of experience he would ... accept as in part an ideological illusion, but what he wants to retrieve is a recognition of the life processes, the praxis, that precedes analysis.' (1989: 35) Ideology, for Williams, does contain - in the sense of shape, limit - experience; but there still occurs the life-process, involving an effort after meaning, in the telling of stories in the widest sense of the notion. This sense takes us to his idea of the cultural itself. The idea of culture, as Williams sees it, lies in an acceptance of it as 'a constitutive social process, creating specific and different ways of life'. (1977:19) Regarding it precisely as a process - and here the idea of structure of feeling as a way of seeing and experiencing emerges as a fluid and changing state: what Williams calls 'in solution' - places a strong focus on agency. One area of agency is the act of writing. So it is that literature and writing produces a structure of feeling, which is open to critical analysis, and is privileged as a site where a specific sensibility can be encountered. This idea of sensibility takes us once again close to what Bourdieu means by habitus, and there are interesting cross-overs, but also significant differences, between the two theorists.

7.3 Williams sees fixed forms - accepted ways of going about things: a dominant ideology or indeed the habitus - locked in tension within the complexity of practical experience (1977: 130). But this practical experience does not constitute the spontaneous orientation to the world implied by Bourdieu's concept of habitus. Using this construct, Williams states that he is 'talking about characteristic elements of impulse, restraint and tone; specifically affective elements of consciousness and relationships; not feeling against thought, but thought as felt and feeling as thought: practical consciousness of a present kind, in a living and interrelated continuity'. (1977: 132) This quote takes us very near to Sayer's discussions around the cognitive dimension of emotion. "Feeling" exists within a framework, or structure, articulated as social and personal, the result of intersubjective social relations and processes, and in this sense there is something resolutely dialogic bound up with the concept of structure of feeling. Often this is a condition of preemergence, however. As practical consciousness it differs from official consciousness in that it is 'being lived, and not only what is thought is being lived.' (1977: 131) Williams denotes this as 'a kind of feeling and thinking which is indeed social and material, but each in an embryonic phase before it can become a fully articulate and defined exchange.' (1977: 131)

7.4 Williams suggests that the best method for thinking this concept is through the literary term 'style', echoing Bakhtin/Volosinov and his concept of register. While not actually a speech-genre in Bakhtinian terms, the importance of language in our understanding of structure of feeling remains crucial. If no two generation speak the same language the differences can be defined in terms of new, emerging articulations, characterised by 'additions, deletions and modifications' (1977: 131), and yet, in the notion of 'style', something more general has occurred within the very forms and grammar of experience itself. And what becomes important to identify, in a range of social/cultural forms - from buildings and fashion, to drama and literary production - 'is a particular quality of social experience and relationship, historically distinct from other particular qualities, which gives the sense of a generation of a period.' (1977: 131) What can be witnessed is a kind of pattern within the overall complex; a pattern of experience denoted by levels of continuity and discontinuity.

7.5 Art and literature can bear witness to this, so that the process of writing becomes something more than the author's individual expression, or "vision," as it necessarily engages with wider historical structures or events with which artistic endeavour is always bound up. Narrative then becomes a socially symbolic act. In this context, feeling suggests process and unfinished-ness - articulation finds uneasy expression through certain images and ideas that for Williams hover at the very 'edge of semantic availability'. (1977: 132) This tension offers to the critic the source of an often quite privileged insight on history. In particularly acute ways, then, subjects struggle to articulate shared meanings and feelings at the level of lived experience, speaking a structure of feeling through various modes of address in possible dispute, or dissonance, with dominant ways of seeing. This is not necessarily to suggest an unproblematic and homogeneous structure of feeling in some simple way related to class, for instance. Other crucial co-ordinates intersect with any 
understanding of structure of feeling, most profoundly, perhaps, those of gender and generation. Moreover, no single, or common, structure of feeling will be evident; this difference Williams places within a framework of the dominant, emergent and residual.

7.6 Williams's suggests that structure of feeling represents a cultural hypothesis derived 'from attempts to understand such elements and their connections in a generation or period, and needing always to be returned, interactively, to such evidence.' (1977: 133) Art and literature are indeed unique sources for examining structure of feeling, but this does not require us to restrict its uses to these areas. Artistic practice, Williams seems to argue at this point, escapes the contaminating effects of ideology and this is the real source and special nature of the aesthetic itself. This is an intriguing position, though largely an untenable one. Cultural production is bound up with ideological production. Yet what Williams is perhaps really getting at here, alongside critics like Pierre Macherey (1966) and Terry Eagleton (1976), is that the special nature of literature rests with its propensity to rework ideology, present it at one remove, in the process of which revealing an ideological matrix within an emergent structure of feeling well before it can become a formalised entity, a fixed form, within the social itself. Thus structure of feeling in this context can be 'specifically related to the evidence of forms and conventions - semantic figures - which, in art and literature, are often among the very first indications that such a new structure of feeling is forming.' (1977: 133) Williams's own well-known example is of the English novelists of the 1840s. This specific formation of writers - with no obvious connections between them - are seen to adopt or adapt identifiable conventions to express a structure of feeling focused on the exploration of community, representing the writers' response to radical social change. In the throes of the Industrial Revolution, it become urgent that 'class relations, including class conflict, [constitute] the conscious material of fiction,' even if this dynamic is addressed 'precisely so it can be reconciled or evaded.' (Williams 1981: 163) But it is within this evasion, and the modes through which the ambiguity occurs, that the tension emerges. If the dominant ideology of the early Victorian period ascribed personal failing to poverty, debt and illegitimacy, the formation of writers which included Gaskell, Dickens and Bronte exposed these conditions as deriving from a source that was instead social and economic - 'producing an alternative position, relating such exposure to the nature of the social order', a perspective that was only later more generally formed. (1977: 134) Then it offered the explanation or critique at a 'reduced tension: the social explanation fully admitted.' (1977: 134)

7.7 Structure of feeling, then, can be analysable in the literary text, often detected when common conventions used to articulate experience are partly re-orientated or cast aside altogether. Thus 'there are cases where the structure of feeling which is tangible in a particular set of works is undoubtedly an articulation of an area of experience which lies beyond them ...' This is 'especially evident at those specific and historically definable moments when new work produces a sudden shock of recognition. What must be happening on those occasions is that an experience which is really very wide suddenly finds a semantic figure which articulates it.' (Williams 1979: 162) Discovering these 'semantic figures' helps us to understand writing's entanglement with historical change. And this idea of entanglement is appropriate. Defining entanglement as some 'embarrassing mess' (a possible interpretation offered to me by my computer's thesaurus) reminds us that writing is both implicated within, as it at variable levels exposes, ideology, thus insinuating the social and historical within what can be defined - following Fredric Jameson (1981) - as the text's political unconscious.

7.8 As a mode of cultural analysis structure of feeling provides evidence about the vital, and lived, experiences or attitudes of a group or of a society in a particular period, defining a particular quality of social action, within uneven processes of historical change and continuity. Interaction occurs between the official consciousness of a period, duly codified and formalised (in the sense of a dominant ideology), and what Williams calls 'practical consciousness' - and this relationship remains a site of potential fracture and contradiction. Any opposition to the period's official consciousness is experienced as a 'kind of feeling and thinking which is indeed social and material'; and the term 'feeling' is appropriated to make a distinction from ideology as "world view" (the ideology of a particular class, say), because Williams is keen to identify meanings and values that are actually lived and felt, 'and the relation between these and formal or systematic beliefs'. (1977: 132) Here, our sense of structure of feeling moves beyond the specificities of the literary text to an analysis of the wider culture and cultural formations more generally. The essentially dialogic relationship observable in the previous quote - which implies a Bakhtinian struggle over meaning itself, couched in an ideological sense in which ways of seeing are allied with hegemonic power relations constantly striving to re-new, or reinforce themselves - allows us to think of structure of feeling in relation to the social and historical and, more pertinently perhaps, to notions of community.

7.9 As a key word in Williams's oeuve, community stands out. The relationship between self and other takes shape within community: here the subject acquires knowledge of herself/himself within a wider, and often determining (or 'limiting', to use Williams's word for defining ideological processes) social context. Thus it is that structure of feeling becomes a mediating term to define the continuing interaction between the individual and the social, standing as 'socio-historical description and development ... integral to 
[Williams's] understanding of community'; stressing at the same time the 'process of communication by which interaction becomes possible'. (Eldridge and Eldridge 1994: 140) The concept embodies a structure of past, present and future which can in turn lead the subject 'towards a new way of seeing and/or feeling, resulting in the familiar appearing strange or the strange becoming familiar.' (Williams 1977: 141) Through such processes social change occurs; shaped by actors as it shapes them.

7.10 How can some of the above arguments be used for exploring the experiences of class? There is in the humanities and some key areas of the social sciences a distinct and productive turn to the study of autobiography. This has been particularly evident and fruitful in studies within feminism. My intention now, in concluding this article, is to look at autobiography and the working class, and I will take as my primary source a piece of autobiographical writing which captures in its articulation many of the themes, assertion and ideas worked through in the above discussion. There is something particular about autobiography, and it lies in the form's insistence on presence and, perhaps more importantly, its association with the key concept of experience. Alfred Williams's autobiography - which I discuss below - was published in 1987, at the height of Thatcherite hegemony and amid the calls for the end, or the demise, or the redundancy, of class to which I referred in my introduction to this piece. Such writing, along with the work of women scholars cited earlier, suggests that writing about class around this period - indeed, working-class writing as a particular cultural formation in itself - remained, and largely remains, writing from the margins. Thus Alfred Williams's story, and the work I have highlighted as part of the process of reinvigorating class analysis in recent times, constitutes, in a very clear sense, a counter-hegemonic practice.

\section{Announcing the Self: Class and Autobiography}

8.1 I have chosen to examine a piece of writing published outside the mainstream market. Local publishing projects in Britain, developing since the mid-1970s, have enabled local people to write and record their own experiences, in a context outside mainstream commercial publishing. As an alternative cultural formation, the Federation of Worker Writers and Community Publishers encourages people to become the producers of writing rather than simply consumers of representations offered through conventional publishing and other media; with the 'aim to create a living, non-competitive popular history and literature. By the people, for the people'. (Morley and Worpole 1981: 17) In a number of respects, the aim is to democratise literature (and in the process question exactly what literature is, or is meant to be); writing is produced and consumed within and for communities, from specific regional bases, by a process that is collective, shared and supportive. Work takes the form of anthologies or separate projects, workshops are organised where writing and reading sessions take place and where work in progress can be discussed. Poetry and autobiography are favoured forms of articulation for those writing within the movement. The form of autobiography has a number of advantages: firstly, for fledgling writers it suggests a mode of writing which provides a resource of ready available material with which to shape a narrative; secondly, and more significantly, it constitutes a form which enables the subject to speak and to assert his or her presence in a specific time and place: in short, in history.

8.2 The working-class autobiographies produced through community publishers are not only marked by moments of "self-definition", but often disclose what has been referred to as 'acts of collective recovery ... premised on notions of a collective past' (Dentith and Dodd 1988: 9), an emphasis rarely evident in bourgeois autobiography, and more often than not absent from the autobiographies of working-class people who have made an early 'upward' transition from their class of origin. Thus writing is associated with making sense of a life and defining these lived experiences as important, common or shared. But the narratives encode, too, a range of desires - sometimes explicit, often implicit. On one level there is a sense in some of the writing of a need to pass on past experiences to a younger generation: to generate and convey useful knowledge. The text I have chosen for analysis contains these tendencies within its overall narrative thrust, but discloses other perspectives, demands and articulations, too, which relate strongly to the arguments I have outlined above.

8.3 In To Live It Is To Know It (1987), Alfred Williams, a retired, black railway worker, stresses from the outset the importance of lived experience, hoping that 'maybe things from my life some use to younger people ... I an ordinary man, but what I know, I did not learn in books, I did learn from living it'. (Williams 1987: 7) These experiences are recorded and documented throughout in the British-Caribbean dialect that is his natural tongue. Thus he values his experiences as a black man domiciled in Britain and as a worker; positions through which he has made sense of his life. Evident is an active class consciousness at work in the narrative, produced by his experiences and now mediating his account of them. Of his early years, he says 'I learn during those years [of working for plantation owners]: the rich kind of people get rich, the rich kind of people stay rich. And I look about me today, in England, in 1987, and I think this; for the poor people this country is becoming like the West Indies'. (1987: 17)

8.4 Common to a number of working-class autobiographies an important organising principle is found in the experiences of work and the significance of locality. Williams stresses the hardship of proletarian labour as 
he documents early life in Jamaica, where work was close to the experience of slavery but vital for survival; he describes emigration to England where work was hard to come by because of prejudice. Finally settling in Yorkshire, he finds employment on the railways and gets married, but life is still not easy:

All my life I work hard, sometime two job. When I get home I must sleep, or maybe I go to pub and try to forget work, try to forget how I treat for being coloured, try to find a little enjoyment. (Williams 1987: 50)

8.5 His memories of work in Jamaica are no better:

This is one of the hardest and worst positions to be in; to work and to live in. Any time of the night and day the boss come and knock on your door. Any time. And when the boss knock, you work, because if you don't work, then you have no job ... So I was semi-slave. (Williams 1987: 13)

8.6 Dignity, recognition and respect circulate precariously in these statements, as he struggles with the conditions of his life to make it meaningful. But as an immigrant living in Britain, Williams necessarily has a more ambiguous relationship with both the significance of locality and nation, which impinges also upon ideas of class-belongingness. The identity sustained for a working-class person by a sense of place is instead undercut by the complex experiences of diaspora. It is this diaspora structure of feeling that encodes an emergent, or alternative, way of seeing the world. But this response is interestingly cross-cut with other - and for him complementary - perspectives.

8.7 Williams reveals his own individual struggle over whether to leave Jamaica for the 'Mother-Country': 'All my life in Jamaica people is telling me, Come to England. Come to Mother-Country, it flow with milk and honey. Van come round with a film show in it: Come to England. Come to England'. (33) He nevertheless remains 'betwitx and between', wary of the rhetoric, yet finally enticed to leave his own culture for an alien one.

I'm not going to hide the truth as I know it. When we come to England it was Hell here. Coloured always get worse. Some days I am blasted bitter about life. When I think of some of the things life give out to me ... Life is good and life is Hell and it the same life. (Williams 1987: 39)

8.8 The language is seen to move ambivalently from 'l' to 'we' and back to 'l'. The shifting pronouns suggest that Williams understands his experiences not only on an individual level, but in a collective sense.

However, here the mode of address is as a black person speaking to, with and for other black immigrants in a complex alignment. This returns us to the ideas on language and the dialogic developed by Bakhtin/Voloshinov. The writers, discussing verbal interaction and orientation, described this structure as the 'I-experience' and 'we-experience', and much of Williams's narrative corresponds to this formulation. Here the self is understood only in relation to others, in acts of both identification and dis-identification. Thus language, or the 'word ... is the product of the reciprocal relationship between speaker and listener, addresser and addressee'; so that 'I give myself verbal shape from another's point of view, ultimately, from the point of view of the community to which I belong.' (in Dentith 1995: 130) But the utterance, or speechact, takes its shape and its intelligibility within specific contexts and historical and social situations. The relevant historical situation here is the one of being 'betwitx and between', straddled between two cultures, a definition corresponding to Homi Bhabha's "Third Space", a location from which, for Bhabha, the subaltern is destined to speak. (Bhabha 1994: 38-9) However, the structure of the utterance thrusts towards Bakhtin/Volosinov's more inclusive we-experience, so that the experience of diaspora for Williams is not something borne in isolation, or individually, but recognized through what Bakhtin/Volosinov calls a 'united collective' (in Dentith 1995: 133), and this facilitates an utterance marked 'predominantly by overtones of active and self-confident protest with no basis for humble and submissive intonation.' (in 1995: 133) This structure of feeling characterises Williams's writing throughout, though interestingly the speaking voice takes up a number of positions in the narrative, not only that of the migrant voice, but that of a class conscious worker, which he identifies and articulates also as a 'united collective.'

8.9 To remain with Bakhtin/Volosinov, it is possible to understanding autobiography as a kind of speechgenre in itself, a discursive practice, with its own specific conventions, registers and forms. Williams's work both adopts and adapts some of these conventions. Thus the rhetoric of continuity, a convention predicated of types of autobiography, yields to the more ambivalent experience of passage, and thus of dispacement. Identity is negotiated through a process of transition and transmigration, producing a structure of feeling which cannot always be successfully accommodated within traditional autobiographical forms. Williams tells the story of his displacement and his struggle to re-place or re-situate himself within a 'Mother-country' whose own selective history and invented traditions will marginalise or degrade his existence, and it is as testimony to this essentially moral and political struggle that the autobiography stands. As we suggested 
above, the term heteroglossia describes the multiple voices within a single language and culture; voices which express in tone and structure different evaluative accents and positions corresponding to social classes or groups, and in which the ideological struggles of the oppressed to resist incorporation within, or obliteration by, the dominant discourse and power occurs. As Edward Said has argued, 'The power to narrate, or to block other narratives from forming and emerging' represents a crucial mode of cultural hegemony (Said 1993: viii). In both content and form, Williams's narrative resists the "received" modes of expression, which he deems insufficient for articulating his self and his experiences. The vernacular of black (working-class) Britain instead constitutes a purer language which encodes the experience of struggle (his own and that of others - the 'we' he articulates), while striving to demystify the stories told 'to keep rich people rich and poor people poor'. (1987: 51) The autobiography disturbs the homogenisation of experience which hegemonic modes of articulating stories of cultural belonging and national identity attempt to impose, whilst at the same time working to acknowledge and celebrate solidarities with others. Williams's view of Britain is a multi-cultural one, reflecting his experience as part of a generation of post-war immigrants to the country; though he understands that a person's place within the imagined community involves the various struggles of the subordinated for justice and recognition. The text represents, therefore, one man's attempt to rescue the black working-class experience from the enormous condescension of posterity; yet throughout, Williams identifies with those he terms 'ordinary people', disclosing what Raymond Williams once called a powerful desire for a 'common betterment'. (Williams 1958: 331)

8.10 He writes of his early world on the plantation as both intimate and "other": 'I don't know who Edwin Charley was, I think he was an Englishman, or American, but we didn't know him, we did not see him, he just like Tate and Lyle'. (1958:14) Power relations such as these, Williams insists, oppress and degrade human lives. On one level, his motive for writing is to celebrate his own agency, the overcoming of harsh conditions and to insist on his survival and his presence; but as a worker he stresses also the need for a collective response against the rich and powerful, both then and in the present juncture. It was only the Union's arrival that made any significant difference to the lives of the plantation workers: 'Things change when the Union form. The big plantation had to keep to the union rule ...' (1958: 14) Back in the present, he warns, 'If Union broke in England, then you will come to know what is Hell ...' (1958: 47) Williams's reference to the historic moment and, more specifically, to economic class struggle, is a response to Thatcherism's attacks on trade unions in the 1980s, which he sees as attacks on working-class living conditions, its very existence. He warns that 'there is nothing I can do, or you can do, unless we get together.' (1958: 47) And the 'we' here points to a different referent, another 'we-experience', which illustrates my earlier point that the narrative itself is composed of a range of different but interconnected subject positions. At this point, Williams makes discursive a particular ethos and set of values which derive from class experience and which are spoken at that moment of danger that Benjamin alluded to, always close at hand for the exploited or oppressed - articulating a structure of feeling in tension with those formalized beliefs and dominant discourses which came to be coded then and later as Thatcherism.

8.11 Thus, for the writer, there exists no insurmountable conflict between his difference as a black man and his identity as a worker. Collective action by the workers themselves will prevent those who 'have money' from imposing their economy on others. What might be identified as an emergent and complex structure of feeling here explores difference whilst proposing solidarity as a remedy to the injustice and exploitation suffered by the subaltern and subordinate. While telling an individual story, the narrative's mode of address transcends individualism. To do this, it mobilises collective modes of identification predicated on experiences refracted through the prisms of both race and class, and insists in the end not so much on the celebration of difference, but on the imperative of forming and recognizing what I have called elsewhere complex solidarities. (Kirk 2003)

\section{Conclusion}

9.1 While considering the significant contribution of Andrew Sayer's The Moral Significance of Class for reinvigorating our understanding of class and for willing our engagement and recognition of the effects of inequality and injustice, this paper has attempted to develop and build on some of the key arguments in this work by drawing on the ideas of other social and cultural theorists and, more pertinently perhaps, some writing from the working-class itself. Sayer points out towards the close of his book that 'having once been the fundamental source and subject of conflict in the political culture of capitalism, class inequality is now the problem that dare not speak its name.' (Sayer 2005: 224) In academic and political circles up until recently this may have been the case; for those living class 'on the pulse', in Annette Kuhn's compelling phrase (1995), things are seen quite differently.

\section{Notes}

${ }^{1}$ In many respects this was begun in 1986 with Carolyn Steedman's Landscape for a Good Woman , an 
early intervention in the 'end of class' debate. Other works include: Valerie Walkerdine, Schoolgirl Fictions (1991); Annette Kuhn, Family Secrets: Acts of Memory and Imagination (1995); and Beverley Skeggs, Formations of Class and Gender (1997). Skeggs's recent Class, Self, Culture (2004) explores similar themes to Sayer, and flags up the significance of the symbolic in understanding class.

${ }^{2}$ It is not my intention to get into the debate about authorship which accompanies discussion of the work of Bakhtin/Volosinov - here the two writers are conjoined by a forward slash to imply that the ideas drawn on belong to one or the other, or both.

\section{References}

BHABHA, Homi. (1994) The Location of Culture. Routledge: London.

BECK, Ulrich. (1986) Risk Society. Sage: London.

BOURDIEU, Pierre. (1993) Sociology in Question. Sage: London.

BOURDIEU, Pierre. (1999) The Weight of the World. Polity: Cambridge.

CHARLESWORTH, Simon (2000) A Phenomenology of Working Class Experience. Cambridge University Press: Cambridge.

DENTITH, Simon. (1995) Bakhtinian Thought: An Introductory Reader. Routledge: London.

DENTITH, Simon and Dodd, Philip. (1988) 'The Uses of Autobiography', Literature and History 14-1: pp. 419.

EAGLETON, Terry. (1976) Criticism and Ideology. New Left Book: London.

ELDRIDGE, John and Eldridge, Elizabeth. (1994) Raymond Williams: Making Connection. Routledge: London.

GIDDENS, Anthony. (1991) Modernity and Self-Identity: Self and Other in the late Modern Age . Polity: Cambridge.

HONNETH, Axel. (2001) 'Recognition or Redistribution? Changing Perspectives on the Moral Order of Society', Theory, Culture \& Society Vol 18 (2-3): pp. 43-55.

JAMESON, Fredric. (1981) The Political Unconscious: Narrative as a Socially Symbolic Act . Routledge: London.

KIRK, John. (2003) Twentieth Century Writing and the British Working Class . University of Wales Press: Cardiff.

KUHN, Annette. (1995) Family Secrets: Acts of Memory and Imagination . Verso: London.

MACHEREY, Pierre. (1966) A Theory of Literary Production . Routledge and Kegan Paul: London.

MEDHURST, Andy. (2000) 'If Anywhere: Class Identifications and Cultural Studies Academics', in Sally Munt (ed). Cultural Studies and the Working Class: Subject to Change. Cassell: London.

MIDDLETON, Peter. (1989) 'Why Structure of Feeling?', News from Nowhere 6, pp. 30-42.

MORLEY, David and Worpole, Ken. (1981) The Republic of Letters. Comedia: London.

SAID, Edward. (1993) Culture and Imperialism. Vintage: London.

SAYER, Andrew. (2005) The Moral Significance of Class . Routledge: London.

SKEGGS, Beverley. (1997) Formations of Class and Gender: Becoming Respectable. Sage: London.

SKEGGS, Beverley. (2004) Class, Self, Culture. Routledge: London.

STEEDMAN, Carolyn. (1986) Landscape for a Good Woman: A Tale of Two Lives . Virago: London.

WALKERDINE, Valerie. (1991) Schoolgirl Fictions. Verso: 1991. 
WILLIAMS, Alfred (1987) To Live It Is To Know It. Yorkshire Arts Circus: Castleton.

WILLIAMS, Raymond. (1958) Culture and Society. Chatto and Windus: London

WILLIAMS, Raymond (1977) Marxism and Literature. Oxford University Press: Oxford.

WILLIAMS, Raymond (1979) Politics and Letters. New Left Books: London.

WILLIAMS, Raymond (1981) Writing in Society. Verso: London. 